\title{
Oral Complication of Chemotherapy
}

National Cancer Institute

\section{Source}

National Cancer Institute. Oral Complication of Chemotherapy. NCI Thesaurus. Code C115321.

Any oral disorder occurring as a consequence of chemotherapy treatment. 